\title{
Effects of eicosapentaenoic acid ethyl ester on visfatin and apelin in lean and overweight (cafeteria diet-fed) rats
}

\author{
Nerea Pérez-Echarri, Patricia Pérez-Matute, Beatriz Marcos-Gómez, J. Alfredo Martínez \\ and María J. Moreno-Aliaga* \\ Department of Nutrition, Food Science, Physiology and Toxicology, University of Navarra, 31008 Pamplona, Spain
}

(Received 14 January 2008 - Revised 13 June 2008 - Accepted 30 June 2008 - First published online 28 August 2008)

Previous studies have demonstrated that the $n-3$ fatty acid EPA improves insulin resistance induced by high-fat diets. The aim of the present study was to investigate the potential role of visfatin and apelin in the insulin-sensitising effects of EPA ethyl ester. The effects of EPA on muscle and adipose GLUT mRNA, as well as on liver glucokinase (GK) and glucose-6-phosphatase (G6Pase) activity, were investigated. Male Wistar rats fed on a standard diet or a high-fat cafeteria diet were daily treated by oral administration with EPA ethyl ester $(1 \mathrm{~g} / \mathrm{kg})$ for 5 weeks. A significant decrease $(P<0.01)$ in white adipose tissue (WAT) visfatin mRNA levels was found in the cafeteria-fed rats, which was reversed by EPA administration $(P<0.05)$. Moreover, a negative relationship was observed between homeostatic model assessment (HOMA) and the visfatin:total WAT ratio. In contrast, cafeteria-diet feeding caused a significant increase $(P<0 \cdot 01)$ in apelin mRNA in visceral WAT. EPA increased $(P<0 \cdot 01)$ apelin gene expression, and a negative relationship between HOMA index with visceral apelin mRNA and serum apelin:total WAT ratio was also observed. EPA treatment did not induce changes in skeletal muscle GLUT1, GLUT4 or insulin receptor mRNA levels. Neither liver GK and G6Pase activity nor the GK:G6Pase ratio was modified by EPA. These data suggest that somehow the insulin-sensitising effects of EPA could be related to its stimulatory action on both visfatin and apelin gene expression in visceral fat, while changes in skeletal muscle GLUT, as well as in hepatic glucose production, are not likely to be the main contributing factors in the improvement in insulin resistance induced by EPA.

Insulin resistance: Adipose tissue: Liver: Skeletal muscle

Obesity is considered to be one of the major risk factors related to insulin resistance onset ${ }^{(1)}$. However, not all types of dietary fats appear to be as obesogenic and to produce insulin resistance. In fact, there is much evidence suggesting that the intake of $n-3$ fatty acids, especially EPA, produces some improvements in insulin resistance and obesity features in several models of obesity and diabetes in rodents ${ }^{(2-5)}$. However, the ultimate mechanisms sustaining the protective effects of $n-3$ fatty acids are still unclear.

In this context, it is well known that adipose tissue is able to synthesise and secrete adipokines that can modulate insulin sensitivity both locally and in other organs ${ }^{(6)}$. In fact, it has been hypothesised that the regulation of these adipokines by n-3 fatty acids could mediate their beneficial effects on insulin resistance. For example, it was recently reported that EPA administration increases the ability of adipocytes to produce adiponectin, which could contribute to the insulin-sensitising properties of this fatty $\operatorname{acid}^{(4,7,8)}$.

The recent identification of two new adipokines, visfatin and apelin, with an important potential role in insulin resistance, has led to investigation of the effects of $n-3$ fatty acids on their regulation. Visfatin was recently identified as a secreted protein expressed and regulated in adipose tissue with a predominant abundance in visceral fat depots ${ }^{(9)}$. An insulin-like action of this adipokine was initially reported both in vivo and in vitro due to a specific binding of visfatin with the insulin receptor ${ }^{(9)}$. However, other studies found that visfatin does not exert any insulin-mimetic effects ${ }^{(10)}$. It has been reported that expression and circulating levels of visfatin increase in obesity and diabetes ${ }^{(9,11,12)}$; however, there are some controversial results concerning these features ${ }^{(13,14)}$.

Regarding apelin, it has been shown that this adipokine is up-regulated in rodents and man during obesity, and that a strong relationship exists between adipocyte-secreted apelin and insulin levels ${ }^{(15-17)}$. In fact, plasma apelin concentrations have been associated with hyperinsulinaemia, and the insulindeficient mice (streptotocin-treated) showed lower mRNA levels of apelin as compared with controls ${ }^{(15)}$. It has been hypothesised that over-production of apelin in the obese could be one of the last protective defences before the emergence of obesity-related disorders such as insulin resistance and type 2 diabetes ${ }^{(18)}$.

In addition to their effects on adipokines, it has been suggested that $n-3$ fatty acids could also exert their positive actions on insulin sensitivity by modifying the levels of GLUT (GLUT1 and GLUT 4) in muscle and adipose tissue ${ }^{(3,19)}$.

Abbreviations: $\mathrm{C}_{t}$, cycle threshold; GK, glucokinase; G6Pase, glucose-6-phosphatase; HOMA, homeostatic model assessment; Tris, 2-amino-2-hydroxymethylpropane-1,3-diol; WAT, white adipose tissue.

* Corresponding author: Dr M. J. Moreno-Aliaga, fax +34 948425649, email mjmoreno@unav.es 
Furthermore, $n-3$ fatty acids could also improve hyperglycaemia and hyperinsulinaemia by regulating the hepatic enzymes involved in glucose phosphorylation (glucokinase; GK) or dephosphorylation (glucose-6-phosphatase; G6Pase), which control glucose utilisation and production by this $\operatorname{organ}^{(20,21)}$.

In the present study, we investigated the effects of the $n-3$ fatty acid EPA on visfatin and apelin circulating concentrations and mRNA expression levels in lean and overweight rats, as well as the effect of EPA on muscle and adipose GLUT mRNA and liver GK and G6Pase activity. We demonstrate for the first time that EPA stimulates visfatin and apelin adipose tissue production, which could be involved in its properties to protect against the development of insulin resistance.

\section{Experimental methods}

\section{Animals and treatment}

Twenty-nine male Wistar rats (aged 6 weeks), obtained from the Centre of Applied Pharmacology (CIFA, Pamplona, Spain), were housed (two or three per cage) in a temperaturecontrolled room $\left(22 \pm 2^{\circ} \mathrm{C}\right)$ with a $12 \mathrm{~h}$ light-dark cycle. All experimental procedures were performed under protocols approved by the University Ethics Committee for the use of laboratory animals, according to the National and Institutional Guidelines for Animal Care and Use. Animals were distributed in four experimental groups: control, control-EPA, overweight and overweight-EPA groups. All animals were maintained in an adaptation period of $4 \mathrm{~d}$ on a chow diet (Rodent Toxicology Diet; B\&K Universal, Hull, UK) and given deionised water ad libitum. After this period of time, control and control-EPA groups were fed a standard pelleted diet (Rodent Toxicology Diet; B\&K Universal) containing $76 \%$ of carbohydrates, $6 \%$ of lipids and $18 \%$ of proteins $(1515 \mathrm{~kJ} / 100 \mathrm{~g}$ (362 kcal/ $100 \mathrm{~g})$ ). On the other hand, the overweight and overweightEPA groups were fed a cafeteria diet composed of the following items: pâté, chips, bacon, chocolate, biscuits and pelleted diet $(2: 1: 1: 1: 1: 1 \text {, by wt. })^{(22)}$. The composition of this diet was $9 \%$ energy as protein, $29 \%$ as carbohydrate and $62 \%$ as lipid by dry weight. All the animals had ad libitum access to water and food during 5 weeks. Simultaneously, the controlEPA and overweight-EPA groups were daily treated by oral administration with highly purified EPA ethyl ester $(1 \mathrm{~g} / \mathrm{kg}$ animal weight) during $35 \mathrm{~d}$, whereas the same volume of water was orally administrated to the control and overweight groups, as previously shown in other studies ${ }^{(3,23,24)}$. These control and overweight groups without treatment with any other type of fatty acid (such as SFA with equal chain length as EPA or oleic acid) could be adequately considered as control groups in our study design, as previously published ${ }^{(4)}$, since it has been demonstrated that supplementation with some other fatty acids is able to modify adiposity and the circulating levels of biochemical and hormonal markers planned to be determined in the present study ${ }^{(3)}$.

Body weight and food intake were measured daily. At the end of the experimental period, and after an overnight fast, animal were euthanised by decapitation. The collected gastrocnemius muscle, liver and visceral white adipose tissue (WAT) depots were frozen in liquid $\mathrm{N}_{2}$ and stored at $-80^{\circ} \mathrm{C}^{(4)}$.
RNA analysis and quantitative real-time polymerase chain reaction

Total RNA was extracted from liver, visceral adipose tissue and muscle, according to the Gibco Life Technologies procedure using Trizol (Life Technologies Inc., Grand Island, NY, USA). UV absorbance and integrity gels were used to estimate RNA. After this process, $5 \mu \mathrm{g}$ RNA were treated with DNA-free ${ }^{\mathrm{TM}}$ (Ambion Inc., Streetsville, ON, Canada) in a total reaction volume of $24 \mu \mathrm{l}$ during $30 \mathrm{~min}$ at $37^{\circ} \mathrm{C}$. Of this product, $13 \mu$ l were retrotranscripted to cDNA. Reaction conditions of retrotranscription were as follows: $60 \mathrm{~min}$ at $37^{\circ} \mathrm{C}$ and $5 \mathrm{~min}$ at $95^{\circ} \mathrm{C}$. For real-time PCR amplification, $9 \mu \mathrm{l}$ cDNA per reaction were used.

TaqMan probes for rat apelin (Rn00581093_m1), visfatin/ PBEF1 (Rn00822046_m1), GLUT1 (Rn00593670_m1), GLUT4 (Rn00562597_m1), insulin receptor (Rn00567070_m1) and 18S (Hs99999901_s1) were Assay-on-Demand gene expression products. All of the reagents for real-time PCR analysis of genes (TaqMan RT reagents and TaqMan Universal PCR Master mix) were purchased from Applied Biosystems (Foster City, CA, USA) and the conditions were used according to the manufacturer's protocol. Amplification and detection of specific products were performed with the ABI PRISM 7000HT Sequence Detection System (Applied Biosystems). $18 \mathrm{~S}$ RNA was used as the reference to normalise the expression levels between samples, allowing data to be expressed relative to $18 \mathrm{~S}$ RNA, therefore compensating for any differences in RT efficacy. All standards and samples were analysed in duplicate. Data were obtained as cycle threshold $\left(\mathrm{C}_{\mathrm{t}}\right)$ values (the cycle at where the fluorescence signal emitted is significantly above background levels and is inversely proportional to the initial template copy number) according to the manufacturer's guidelines, and used to determine $\Delta C_{t}$ values $\left(\Delta C_{t}=C_{t}\right.$ of the target gene $-C_{t}$ of the housekeeping gene) of each sample. Fold changes of gene expression were calculated by the $2^{-\Delta \Delta \mathrm{Ct}} \operatorname{method}^{(25)}$.

\section{Enzymic determinations}

Liver GK activity was measured by spectrophotometrical detection of the NADH produced by the glucose-6-phosphate dehydrogenase (G6PDH)-induced dehydrogenation of glucose-6-phosphate in the presence of ATP and NAD ${ }^{+(26)}$. The tissue $(0.6 \mathrm{~g}$ in $10 \mathrm{ml}$ of $50 \mathrm{~mm}$ 2-amino-2-hydroxymethyl-propane-1,3-diol (Tris)- $\mathrm{HCl}$ buffer, $\mathrm{pH}$ 7.4) was homogenised and subsequently centrifuged at $12000 \mathrm{~g}$ for $60 \mathrm{~min}$ at $4^{\circ} \mathrm{C}$, and then the supernatant fractions were collected. Then $10 \mu \mathrm{l}$ of the supernatant fractions were incubated with $5 \cdot 5 \mu \mathrm{l} \mathrm{G6PDH}$ and $985 \mu \mathrm{l}$ of enzymic substrate (100 mM-glucose, $5 \mathrm{~mm}$-ATP, $1 \mathrm{mM}-\mathrm{NAD}$ and $7.5 \mathrm{mM}-\mathrm{MgCl}_{2}$ in $100 \mathrm{~mm}$-Tris- $\mathrm{HCl}$ buffer, $\mathrm{pH} 7.4$ ) during $10 \mathrm{~min}$ in a temperature-controlled bath at $37^{\circ} \mathrm{C}$. Samples were incubated at $4^{\circ} \mathrm{C}$ to stop the reaction, and then the absorbances were measured in a spectrophotometer at $340 \mathrm{~nm}^{(27)}$.

Furthermore, liver G6Pase activity was quantified by measuring the phosphate released from the dephosphorylation of glucose-6-phosphate by G6Pase. Briefly, $0.5 \mathrm{~g}$ liver were homogenised in $4.5 \mathrm{ml} 0.25 \mathrm{M}$-sucrose-HEPES buffer $(\mathrm{pH} \mathrm{7.4)}$ and subsequently centrifuged at $30000 \mathrm{~g}$ for $10 \mathrm{~min}$ at $4^{\circ} \mathrm{C}$. Then the supernatant fraction was centrifuged at 
$100000 \mathrm{~g}$ for $60 \mathrm{~min}$ at $4^{\circ} \mathrm{C}$. The pellet obtained was re-suspended again in the same buffer and the centrifugation was repeated for washing the pellet. This pellet, which contained the microsomes, was then re-suspended in $0.9 \mathrm{ml}$ of the same buffer. A mixture of $100 \mu l$ of microsomes and $400 \mu \mathrm{l}$ of reactive solution (1 mM-glucose-6-phosphate, $0.25 \mathrm{~mm}$ $\mathrm{CaCl}_{2}$ and $1.25 \mathrm{~mm}$-EDTA in $100 \mathrm{~mm}$-Tris- $\mathrm{HCl}$ buffer, $\mathrm{pH}$ $7 \cdot 3$ ) was incubated at $37^{\circ} \mathrm{C}$ during $6 \mathrm{~min}$ in a temperature-controlled shaking bath. To stop the reaction, $2 \mathrm{ml}$ ascorbic acidTCA solution $(2-10 \%$, w/v) were then added. The released phosphate was measured using the method of Fiske-Subbarow $^{(28)}$ and expressed relative to the protein content in the homogenate ${ }^{(29)}$.

\section{Serum visfatin and apelin determinations}

Serum visfatin and apelin levels were measured by ELISA kits from ALPCO Diagnostics Ltd (Salem, NH, USA) and Phoenix Pharmaceuticals Inc. (Belmont, CA, USA) respectively, according to the manufacturers' guidelines.

\section{Statistical analysis}

Statistical differences and interactions were evaluated through a factorial two-way ANOVA (diet $\times$ EPA treatment). When statistically significant differences resulted at the interaction level, a Student's $t$ test was carried out to compare the effects of each treatment (GraphPad Prism; GraphPad Software Inc., San Diego, CA, USA). Furthermore, Pearson correlation analysis was performed to screen potential association between two variables. Differences were considered as statistically significant at $P<0 \cdot 05$.

\section{Results}

Effects of eicosapentaenoic acid ethyl ester on body and fat pad weights and on glucose and insulin serum levels

The administration of EPA ethyl ester $(1 \mathrm{~g} / \mathrm{kg})$ was able to partially prevent the body-weight gain induced by the cafeteria diet in rats (Table 1), although it did not reach statistical significance. Furthermore, EPA treatment tended to decrease the weight of all the fat pads, especially in the group of animals fed with a standard diet. In this sense, a significant reduction $(P<0.05)$ in retroperitonal adipose tissue weight was observed in EPA-treated rats. Although no significant changes were observed in serum glucose levels, EPA treatment induced a significant reduction $(P<0.05)$ in insulin plasma levels (Table 1). Moreover, insulin sensitivity was analysed by assessing the insulin:glucose ratio and the homeostatic model assessment (HOMA) index. The HOMA index was initially defined as an index of insulin resistance in humans ${ }^{(30)}$. Even though HOMA index has not been validated for animal studies ${ }^{(31)}$, several trials have demonstrated that the HOMA index can be useful to compare the resistance to insulin between groups in rodents ${ }^{(4,32-35)}$. Our data revealed that both the insulin:glucose ratio and HOMA index were significantly decreased $(P<0.05)$ in EPA ethyl ester-treated rats, suggesting the ability of EPA supplementation to increase insulin sensitivity (Table 1).

\section{Effects of eicosapentaenoic acid ethyl ester on visfatin circulating and gene expression levels}

A significant decrease $(P<0.01)$ in visfatin mRNA levels in visceral WAT was found in cafeteria-fed rats, which was reversed by EPA ethyl ester administration $(P<0.05)$ (Fig. 1 (a)). However, no significant changes were found in visfatin circulating levels (Fig. 1 (b)), despite the different size of fat depots exhibited by cafeteria-fed rats in comparison with EPA-treated animals. Adipose secretion of several adipokines, such as leptin and adiponectin, has been shown to be dependent on adipose mass size ${ }^{(36)}$. In order to estimate the capacity of adipose tissue to produce visfatin and the involvement of visfatin from fat pads in the total blood concentration, serum levels of this adipokine were corrected for adiposity (visfatin per $\mathrm{g}$ total WAT). Then, a significant decrease in the vistatin:total WAT ratio $(P<0.05)$ was obtained in the cafeteria-fed groups (Fig. 1 (c)). In addition, our present data showed an inverse relationship between serum visfatin levels corrected for adiposity and HOMA index $(r-0.436 ; P<0 \cdot 05)$.

Table 1. Effects of EPA ethyl ester ( $35 \mathrm{~d}$ of treatment) on body and fat weights, and on circulating levels of glucose, insulin and index of insulin resistance in lean and overweight rats ${ }^{\star}$

(Mean values with their standard errors)

\begin{tabular}{|c|c|c|c|c|c|c|c|c|c|c|c|}
\hline & \multicolumn{2}{|c|}{ Control (n 8) } & \multicolumn{2}{|c|}{$\begin{array}{l}\text { Control-EPA } \\
(n 7)\end{array}$} & \multicolumn{2}{|c|}{$\begin{array}{l}\text { Overweight } \\
\quad(n 7)\end{array}$} & \multicolumn{2}{|c|}{$\begin{array}{l}\text { Overweight- } \\
\text { EPA }(n 7)\end{array}$} & \multicolumn{3}{|c|}{$2 \times 2$ ANOVA } \\
\hline & Mean & SE & Mean & SE & Mean & SE & Mean & SE & Diet & EPA & Diet $\times$ EPA \\
\hline Initial body weight (g) & $181 \cdot 1$ & $2 \cdot 4$ & $181 \cdot 2$ & $2 \cdot 3$ & $186 \cdot 2$ & $2 \cdot 4$ & $179 \cdot 1$ & $6 \cdot 6$ & NS & NS & NS \\
\hline Final body weight (g) & $310 \cdot 6$ & $8 \cdot 1$ & $307 \cdot 8$ & 4.4 & 361.5 & 6.4 & $330 \cdot 7$ & $11 \cdot 8$ & $P<0.001$ & NS & NS \\
\hline Body weight gain (g) & $129 \cdot 2$ & $7 \cdot 3$ & $126 \cdot 6$ & 4.8 & $175 \cdot 4$ & $6 \cdot 8$ & $151 \cdot 6$ & $1 \cdot 1$ & $P<0.001$ & NS & NS \\
\hline Retroperitoneal fat $(\mathrm{g})$ & 6.7 & 0.72 & $3 \cdot 8$ & 0.4 & $11 \cdot 2$ & 1.2 & 9.7 & 0.9 & $P<0.001$ & $P<0.05$ & NS \\
\hline Glucose (mM) & $5 \cdot 3$ & 0.2 & $5 \cdot 2$ & 0.2 & $5 \cdot 8$ & 0.2 & $5 \cdot 3$ & 0.2 & $P=0.08$ & NS & NS \\
\hline Insulin ( $\mu$ Units/ml) & $23 \cdot 3$ & 3.9 & $11 \cdot 2$ & 0.8 & $28 \cdot 2$ & $6 \cdot 7$ & $19 \cdot 9$ & $2 \cdot 4$ & NS & $P<0.05$ & NS \\
\hline Insulin:glucose ratio & 4.4 & 0.7 & $2 \cdot 2$ & 0.2 & $5 \cdot 0$ & $1 \cdot 2$ & $3 \cdot 7$ & 0.5 & NS & $P<0.05$ & NS \\
\hline HOMA† & 5.4 & 0.9 & 2.5 & 0.1 & $7 \cdot 1$ & 1.6 & 4.8 & 0.5 & NS & $P<0.05$ & NS \\
\hline
\end{tabular}

HOMA, homeostatic model assessment.

* Data were analysed by a two-way factorial ANOVA.

†HOMA $=$ insulin $(\mu$ Units $) \times$ glucose $(\mathrm{mmol} / \mathrm{l}) / 22 \cdot 5$ 

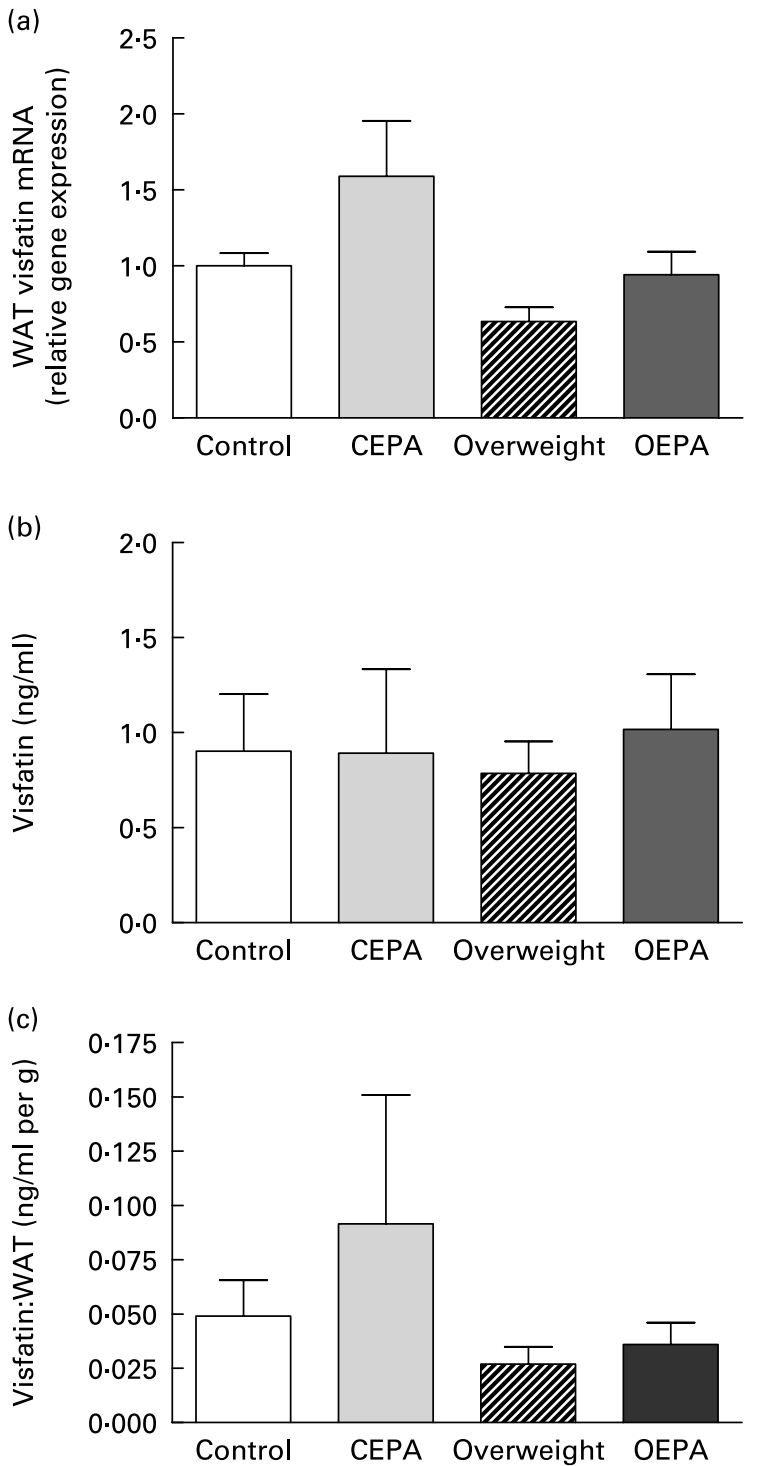

Fig. 1. Effects of EPA ethyl ester on visfatin gene expression and circulating levels in lean and overweight rats. (a) Visfatin mRNA expression levels in visceral white adipose tissue (WAT) obtained by real-time PCR. Data were calculated by the $2^{-\Delta \Delta C t}$ method, where $C_{t}$ is cycle threshold. The mean value for the control group was set at 1 and 18S RNA was used as the reference to normalise the expression levels. The effect of diet was significant $(P<0.01)$, the effect of EPA treatment was significant $(P<0.05)$ and the interaction between diet and EPA treatment was NS. (b) Visfatin circulating levels. The effect of diet was NS, the effect of EPA treatment was NS and the interaction between diet and EPA treatment was NS. (c) Visfatin concentrations expressed per g WAT. The effect of diet was significant $(P<0.05)$, the effect of EPA treatment was NS and the interaction between diet and EPA treatment was NS. Data are means from at least seven independent animals per group, with standard errors represented by vertical bars. Data were analysed by two-way ANOVA. CEPA, control-EPA; OEPA, overweight-EPA.

\section{Effects of eicosapentaenoic acid ethyl ester on apelin circulating and gene expression levels}

In contrast to findings concerning visfatin, cafeteria-diet feeding caused a significant increase $(P<0 \cdot 01)$ in apelin mRNA expression in visceral WAT. Similarly, the administration of EPA ethyl ester also induced a significant increase $(P<0 \cdot 01)$ in apelin gene expression (Fig. 2 (a)). A similar pattern of increased apelin circulating levels in cafeteria-fed rats was observed, although no statistically significant differences were detected (Fig. 2 (b)). Furthermore, our data also showed that both apelin mRNA and the serum apelin:total WAT ratio were negatively correlated $(P<0.05)$ to the HOMA index (Fig. 2 (c) and (d)).

Effects of eicosapentaenoic acid ethyl ester on mRNA levels of glucose transporters (GLUT-1 and GLUT-4) and insulin receptor

As shown in Table 2, no significant effects either by the cafeteria-diet feeding or by EPA administration were observed on GLUT1 and GLUT4 as well as on insulin receptor mRNA levels in gastrocnemious skeletal muscle. However, a significant decrease $(P<0.05)$ in GLUT-1 and GLUT-4 gene expression levels was found in visceral adipose tissue from EPA ethyl ester-treated rats, while no changes were induced in adipose tissue GLUT by the cafeteria-diet feeding (Table 2).

\section{Effects of eicosapentaenoic acid ethyl ester on hepatic glucokinase and glucose-6-phosphatase}

A significant increase $(P<0 \cdot 05)$ in GK activity was observed in cafeteria-fed rats, while no significant changes were found in EPA-treated rats. G6Pase activity, as well as the GK:G6Pase ratio, which reflects hepatic glucose production, was not modified either by the cafeteria diet or EPA treatment (Table 3).

\section{Discussion}

In agreement with previous studies using different models of obesity and/or diabetes ${ }^{(3,4,22,23)}$, our data demonstrate the ability of EPA ethyl ester $(1 \mathrm{~g} / \mathrm{kg})$ to improve insulin sensitivity. A primary goal of the present trial was to find out the potential role of adipose visfatin and apelin, two recently described adipokines, in the insulin-sensitising effects of EPA ethyl ester. Visfatin, which appears to be preferentially produced by visceral adipose tissue, is an adipokine with a controversial capacity to bind and activate the insulin receptor both in vivo and in vitro ${ }^{(9,10)}$. It has also been suggested that visfatin could be a missing link between intra-abdominal obesity and diabetes ${ }^{(9,37)}$. However, controversial results about the role of visfatin in the regulation of glucose metabolism, insulin resistance and obesity situations have been recently described. Thus, although some studies have shown that serum and visceral fat visfatin mRNA levels are increased in obesity and type 2 diabetes $^{(9,11)}$, visfatin gene expression in visceral adipose tissue of Wistar Ottawa Karlsburg W (WOKW) rats, a model of polygenic metabolic syndrome, was similar to that observed in lean control animals ${ }^{(38)}$. Furthermore, some recent trials have even described that visfatin is down-regulated by overfeeding human subjects ${ }^{(13)}$ and that circulating levels of visfatin are negatively correlated with visceral fat in humans genetically predisposed to develop insulin resistance $^{(39)}$. Pagano et al. ${ }^{(14)}$ observed that plasma visfatin levels were reduced in human obesity. Our data suggest that overfeeding with a diet rich in saturated fat impairs visfatin gene transcription in visceral fat. The fact that cafeteria-fed rats exhibit similar serum levels of visfatin to the control rats, despite their higher adiposity, suggests that the ability 
(a)

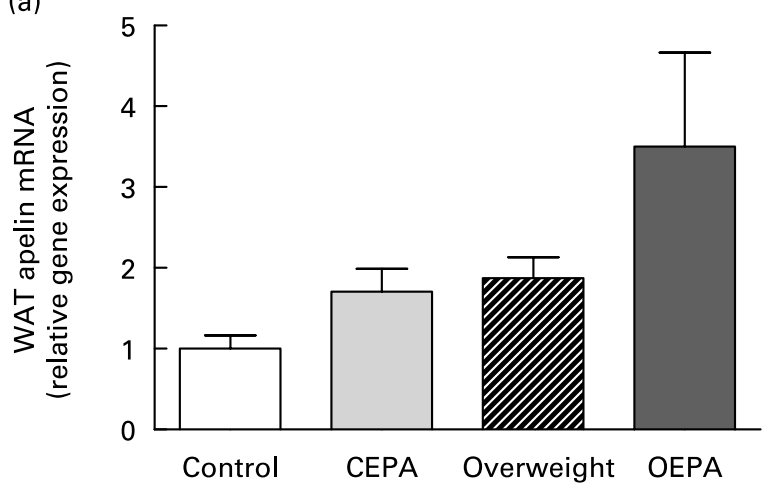

(c)

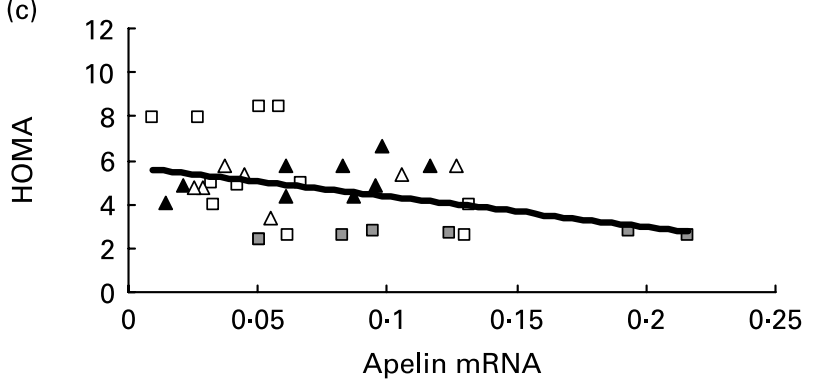

(b)
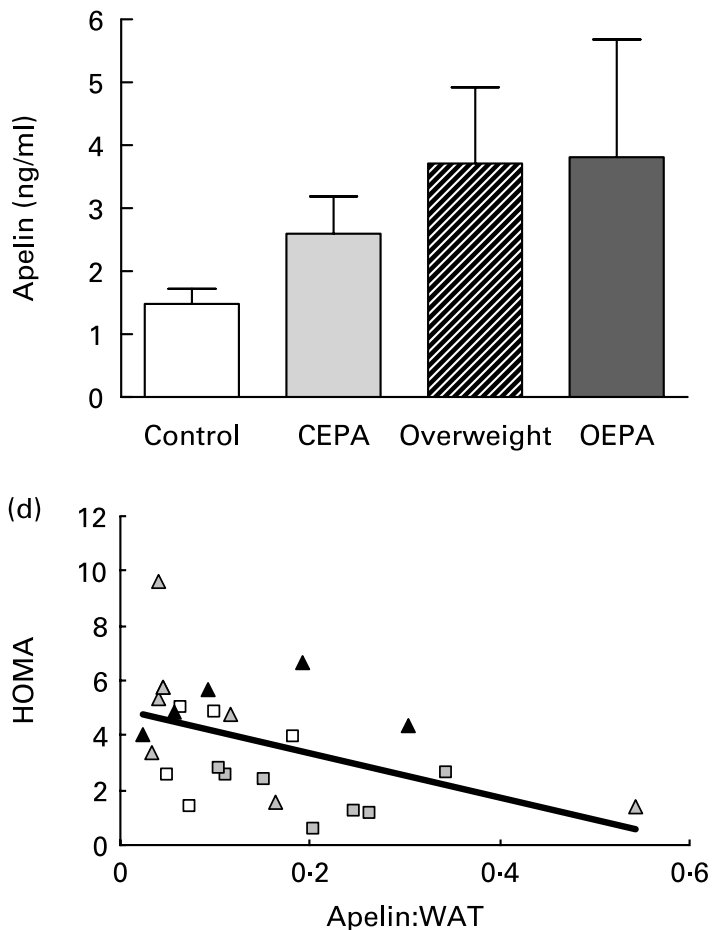

Fig. 2. Effects of EPA ethyl ester on apelin gene expression and circulating levels in lean and overweight rats. (a) Apelin mRNA expression levels in visceral white adipose tissue (WAT) obtained by real-time PCR. Data were calculated by the $2^{-\Delta \Delta C t}$ method, where $C_{t}$ is cycle threshold. The mean value for the control group was set at 1 and 18S RNA was used as the reference to normalise the expression levels. Data are means from at least seven independent animals per group, with standard errors represented by vertical bars. Data were analysed by two-way ANOVA. The effect of diet was significant $(P<0.01)$, the effect of EPA treatment was significant $(P<0.01)$ and the interaction between diet and EPA treatment was NS. CEPA, control-EPA; OEPA, overweight-EPA. (b) Apelin circulating levels. Data are means from at least seven independent animals per group, with standard errors represented by vertical bars. Data were analysed by two-way ANOVA. The effect of diet was NS, the effect of EPA treatment was NS and the interaction between diet and EPA treatment was NS. (c) Correlation between mRNA apelin

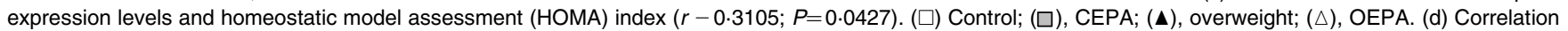
between serum apelin levels corrected for adiposity and HOMA index $(r-0.4645 ; P=0.019)$.

of adipose tissue to produce visfatin is decreased in overweight animals. Indeed, the serum visfatin:total WAT ratio was significantly decreased in these cafeteria-fed animals. Longer periods of cafeteria feeding (more than $35 \mathrm{~d}$ ) would probably be necessary to observe lower circulating levels of visfatin. A lack of concordance between visfatin circulating levels and gene expression in different fat depots has also been observed in other studies. Thus, Pagano et al. ${ }^{(14)}$ found that in human obesity plasma visfatin levels are reduced, whereas visfatin mRNA was significantly higher in visceral fat, together with a down-regulation of the visfatin gene in subcutaneous fat. In contrast, Berndt et al. ${ }^{(40)}$ found that increased visfatin plasma concentrations in obesity correlate positively with visceral and negatively with subcutaneous visfatin mRNA levels. These facts suggest a complex divergent regulation of this adipokine in different fat depots.

Table 2. Effects of EPA ethyl ester on mRNA expression levels of GLUT (GLUT-1 and GLUT-4) and insulin receptor (IR) in skeletal muscle (gastrocnemious) and visceral adipose tissue from lean and overweight rats*

(Mean values with their standard errors)

\begin{tabular}{|c|c|c|c|c|c|c|c|c|c|c|c|}
\hline & \multicolumn{2}{|c|}{ Control (n 8) } & \multicolumn{2}{|c|}{$\begin{array}{c}\text { Control-EPA } \\
(n 7)\end{array}$} & \multicolumn{2}{|c|}{$\begin{array}{l}\text { Overweight } \\
\qquad(n 7)\end{array}$} & \multicolumn{2}{|c|}{$\begin{array}{l}\text { Overweight- } \\
\text { EPA }(n 7)\end{array}$} & \multicolumn{3}{|c|}{$2 \times 2$ ANOVA } \\
\hline & Mean & SE & Mean & SE & Mean & SE & Mean & SE & Diet & EPA & Diet $\times$ EPA \\
\hline Muscle GLUT-1 & 1.00 & 0.34 & $1 \cdot 20$ & 0.27 & 1.09 & 0.17 & 0.98 & 0.12 & NS & NS & NS \\
\hline Muscle GLUT-4 & 1.00 & 0.12 & 0.86 & $0 \cdot 10$ & 0.83 & 0.08 & 0.84 & 0.13 & NS & NS & NS \\
\hline Muscle IR & 1.00 & 0.09 & 0.86 & 0.15 & 0.79 & 0.11 & 0.68 & 0.13 & NS & NS & NS \\
\hline Adipose tissue GLUT-1 & 1.00 & 0.39 & 0.50 & 0.06 & 1.07 & 0.24 & 0.6 & 0.11 & NS & $P<0.05$ & NS \\
\hline Adipose tissue GLUT-4 & 1.00 & $0 \cdot 16$ & 0.73 & 0.16 & 1.69 & 0.86 & 0.65 & 0.14 & NS & $P<0.05$ & NS \\
\hline
\end{tabular}

$\mathrm{C}_{\mathrm{t}}$, cycle threshold.

* Data were calculated by the $2^{-\Delta \Delta C t}$ method. 18S RNA was used as the reference to normalise the expression levels. The mean value for the control group was set at 1 . Data were analysed by a two-way factorial ANOVA. 
Table 3. Effects of EPA ethyl ester on liver glucose-6-phosphatase (G6Pase) and glucokinase (GK) activity, and on G6Pase:GK ratio in lean and overweight rats*

(Mean values with their standard errors)

\begin{tabular}{|c|c|c|c|c|c|c|c|c|c|c|c|}
\hline & \multicolumn{2}{|c|}{ Control (n 8) } & \multicolumn{2}{|c|}{$\begin{array}{c}\text { Control-EPA } \\
(n 7)\end{array}$} & \multicolumn{2}{|c|}{$\begin{array}{l}\text { Overweight } \\
\qquad(n 7)\end{array}$} & \multicolumn{2}{|c|}{$\begin{array}{c}\text { Overweight- } \\
\text { EPA }(n 7)\end{array}$} & \multicolumn{3}{|c|}{$2 \times 2$ ANOVA } \\
\hline & Mean & SE & Mean & SE & Mean & SE & Mean & SE & Diet & EPA & Diet $\times$ EPA \\
\hline G6Pase $(\mathrm{mmol} / \mathrm{g} \times \mathrm{min})$ & 4.66 & 1.69 & 4.78 & 1.43 & 4.38 & 0.71 & 3.98 & 0.69 & NS & NS & NS \\
\hline $\mathrm{GK}(\mathrm{mmol} / \mathrm{g} \times \mathrm{min})$ & 10.98 & 1.37 & $9 \cdot 20$ & 0.47 & $15 \cdot 60$ & 2.63 & $14 \cdot 14$ & 3.05 & $P<0.05$ & NS & NS \\
\hline G6Pase:GK ratio & 0.47 & 0.32 & 0.53 & 0.17 & 0.34 & 0.16 & 0.37 & 0.24 & NS & NS & NS \\
\hline
\end{tabular}

*Data were analysed by a two-way factorial ANOVA.

Moreover, visfatin is also expressed in skeletal muscle, liver and immune cells, whose function is also altered in obesity and it is likely that these tissues may also contribute to serum visfatin concentrations ${ }^{(14,41)}$.

Our data also demonstrate the ability of EPA ethyl ester to prevent the decrease of visfatin gene expression induced by the cafeteria diet. In this context, it has been described that visfatin increased after weight and adiposity loss induced by gastroplastic surgery ${ }^{(42)}$. This finding suggests that the up-regulation of visfatin gene expression in visceral adipose tissue could be due to the reducing effects of EPA treatment on the size of this fat depot ${ }^{(4)}$. However, a direct stimulatory action of EPA on visfatin gene expression cannot be ruled out, similarly to what we have observed with leptin ${ }^{(43)}$.

The physiopathological role of visfatin in the development of insulin resistance remains largely unknown ${ }^{(44)}$. Some studies have suggested that visfatin is not related to insulin resistance in man ${ }^{(14)}$. However, other studies have demonstrated that circulating levels of visfatin are negatively correlated with insulin resistance ${ }^{(39)}$, and its plasma levels are decreased in diabetics compared with non-diabetic subjects $^{(45)}$. The present study shows a negative correlation between the serum visfatin:total WAT ratio and HOMA index, supporting the idea that the increase in visfatin secretion could lead to an improvement in insulin resistance. In fact, our data suggest that the up-regulation of visfatin mRNA levels could contribute, at least in part, to the beneficial actions of treatment with the $n-3$ fatty acid EPA on insulin sensitivity. In this context, a recent study has shown that fatty acids such as oleic and palmitic acids may induce insulin resistance in 3T3-L1 adipocytes and preadipocytes, and that the down-regulation induced by these fatty acids on visfatin mRNA may contribute to impair insulin sensitivity ${ }^{(46)}$. In addition, and in agreement with our trial, it was also described that the up-regulation of visfatin gene expression could be a mechanism through which PPAR- $\alpha$, PPAR- $\gamma$ and PPAR- $\delta$ agonists induced an improvement of insulin sensitivity in genetic obese and insulin-resistant Otsuka LongEvans Tokushima Fatty (OLETF) rats ${ }^{(47)}$ and in Wistar rats fed on a high-fat $\operatorname{diet}^{(48)}$. Moreover, it was described that the increase in circulating concentrations of visfatin after weight loss correlated with the decrease in plasma insulin concentration and HOMA of insulin resistance ${ }^{(42)}$. It has also been demonstrated that the release of the adipocytokine visfatin is regulated by glucose and insulin both in vivo and in vitro ${ }^{(49)}$. In fact, hyperinsulinaemia inhibits visfatin gene expression and secretion ${ }^{(50,51)}$. These facts lead us to suggest that the reduced levels of basal insulin observed after EPA treatment ${ }^{(4)}$ could also contribute to the up-regulation of visfatin gene expression induced by EPA treatment.

Apelin was characterised as a novel adipose-expressed factor that increases during adipocyte differentiation, being also up-regulated in rodent and human obesity ${ }^{(15,45)}$. Our experimental data revealed a significant increase in visceral apelin mRNA levels in cafeteria-fed rats. This is in agreement with a recent study that found positive associations between apelin gene expression levels in subcutaneous adipose tissue and the excessive weight gain induced by cafeteria feeding ${ }^{(51)}$.

In addition, it was recently reported that the increase of some parameters involved in insulin resistance development, such as fat mass, insulin, glucose and lipid plasma levels and TNF- $\alpha$ gene expression, may positively influence apelin circulating levels by regulating its expression ${ }^{(45,52)}$. However, EPA treatment, which has been shown to decrease basal insulin concentrations, HOMA index and adipose TNF- $\alpha$ $\mathrm{mRNA}^{(4)}$ also induced a significant increase in apelin gene expression. Although a similar trend was observed for serum levels, no statistically significant changes were reached, probably because of the high variability of the data. Moreover, if EPA treatment were to last more than 5 weeks or if a higher dose were administered, it might be possible to observe significant changes in apelin, as well as in visfatin, levels.

In this sense, it has previously been hypothesised that overproduction of apelin in the situation of obesity could be one of the last protective defences before type 2 diabetes develops ${ }^{(18)}$. This idea suggests that the improvement in insulin resistance observed in EPA ethyl ester-treated rats could be associated, at least in part, to the increase in apelin gene expression and secretion by adipose tissue. Indeed, our data revealed a negative correlation between both apelin mRNA levels and the serum apelin:total WAT ratio with the HOMA index, supporting the relationship between insulin sensitivity and the amount of apelin produced by adipose tissue. In agreement with this idea, it was recently published that the intraperitoneal administration of apelin increased insulin sensitivity in vivo by influencing circulating adiponectin levels, the expression of brown adipose tissue uncoupling protein 1 and energy expenditure in mice ${ }^{(53)}$.

On the other hand, it has been reported that the expression of GLUT1 and GLUT4 in WAT, as well as GLUT4 in skeletal muscle, is decreased by high-fat feeding and insulin resistance conditions $^{(54-56)}$. In addition, it has been suggested that fish oils could prevent insulin resistance by the prevention of the decreased expression of GLUT4 in both skeletal muscle and adipose tissue ${ }^{(21,56,57)}$. However, in our experimental model of dietinduced obesity, we only found a tendency to decrease GLUT4 
mRNA in skeletal muscle, although this was not statistically significant, and no changes in adipose tissue GLUT1 or GLUT4 mRNA levels were observed in cafeteria-fed rats. Moreover, in the present study the treatment with EPA-ethyl ester during 5 weeks did not induce any significant change in muscle GLUT. This is agreement with the study of Taouis et al. ${ }^{(58)}$, which reported that Wistar rats maintained during 4 weeks with a high-fat diet rich in $n$-3 PUFA showed changes in muscle membrane phospholipids, without affecting muscle GLUT-4 content. However, a previous study from Mori et al. ${ }^{(3)}$ showed that daily administration of EPA ethyl ester during 17-18 weeks caused a significant increase in GLUT4 mRNA in skeletal muscle. Furthermore, and contrary to what could be expected, the present study shows that EPA ethyl ester treatment decreases adipose tissue GLUT1 and GLUT4 mRNA. This could be a mechanism by which EPA prevents glucose entrance into adipocytes and, consequently, reduces the synthesis of new fatty acids in WAT and adiposity, effects mainly observed in the retroperitoneal fat pad ${ }^{(4)}$. In this context, Minami et al. ${ }^{(59)}$ reported that the beneficial effect of EPA ethyl ester on insulin sensitivity seems to be related to a decreased abdominal fat accumulation. Thus, our data showed a significant reduction in the retroperitoneal fat pad $(-25 \%)$ mediated by EPA administration, an effect that could also contribute to improved insulin sensitivity. Taouis et al. ${ }^{(58)}$ observed that GLUT4 mRNA was diminished in rats fed a high-fat diet enriched with $n-6$ fatty acids, while GLUT4 mRNA was unaffected in those enriched with $n-3$. These apparently controversial effects between different studies could be explained by the different durations of the high-fat feeding and the treatment with fish oils or only with highly purified EPA, the composition of the diet, and/or the strain and physiological conditions (normal, obese, diabetic) of rats used in these studies.

It has also been suggested that the protective effect of $n-3$ fatty acids on insulin resistance could be due to the suppression of both the activity and expression of G6Pase, leading to a decrease in excessive hepatic glucose output ${ }^{(21,60)}$. Liver GK is a key enzyme involved in the regulation of glucose storage in hepatocytes ${ }^{(61)}$. However, our experiments did not reveal any significant effect of EPA ethyl ester treatment on GK and G6Pase activity, as well as on the G6Pase:GK ratio (which roughly reflects hepatic glucose production), suggesting that the possible diminution in glucose production by the liver is not the major factor contributing to the improvement in insulin resistance in EPA ethyl ester-treated rats.

In conclusion, our data demonstrate the ability of EPA ethyl ester to prevent the decrease induced by the cafeteria diet in visfatin and apelin mRNA levels in visceral adipose tissue, and suggest that these effects could contribute, at least in part, to the insulin-sensitising effects of EPA. Our data also would indicate that changes in skeletal muscle GLUT, as well as in hepatic glucose production, are not likely to be major factors contributing to the improvement in insulin resistance after EPA ethyl ester treatment.

\section{Acknowledgements}

The present study has been supported in part by the Ministerio de Educación y Ciencia of Spain (AGL 2006-04716/ALI), by the Government of Navarra (Department of Education and Culture) and by Línea Especial de Investigación 'Nutrición, Obesidad y Salud' (University of Navarra/1E/97). N. P.-E. was supported by a doctoral grant from the Government of Navarra (Department of Education). The expert technical assistance of A. Lorente and V. Ciaurriz is gratefully acknowledged. EPA was generously provided by Brudy S.L. (Spain). There are no conflicts of interest. All authors listed have contributed to the work: N. P.-E. wrote the manuscript and performed the experimental work with the collaboration of P. P.-M. (animal treatment) and B. M.-G. (gene expression studies). J. A. M. participated in the experimental design and in the writing of the manuscript. M. J. M.-A. is the main investigator of the projects that support the present study; she participated in the experimental design, contributed to the data analysis and discussion, and the writing of the manuscript.

\section{References}

1. Kopelman PG (2000) Obesity as a medical problem. Nature 404, 635-643.

2. Nobukata H, Ishikawa T, Obata M \& Shibutani Y (2000) Longterm administration of highly purified eicosapentaenoic acid ethyl ester improves the dysfunction of vascular endothelial and smooth muscle cells in male WBN/Kob rats. Metabolism 49, $1588-1591$.

3. Mori Y, Murakawa Y, Katoh S, Hata S, Yokoyama J, Tajima N, Ikeda Y, Nobukata H, Ishikawa T \& Shibutani Y (1997) Influence of highly purified eicosapentaenoic acid ethyl ester on insulin resistance in the Otsuka Long-Evans Tokushima Fatty rat, a model of spontaneous non-insulin-dependent diabetes mellitus. Metabolism 46, 1458-1464.

4. Perez-Matute P, Perez-Echarri N, Martinez JA, Marti A \& Moreno-Aliaga MJ (2007) Eicosapentaenoic acid actions on adiposity and insulin resistance in control and high-fat-fed rats: role of apoptosis, adiponectin and tumour necrosis factor-

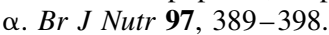

5. Lombardo YB, Hein G \& Chicco A (2007) Metabolic syndrome: effects of $n$-3 PUFAs on a model of dyslipidemia, insulin resistance and adiposity. Lipids 42, 427-437.

6. Fantuzzi G (2005) Adipose tissue, adipokines, and inflammation. J Allergy Clin Immunol 115, 911-919.

7. Flachs $\mathrm{P}$, Mohamed-Ali V, Horakova O, Rossmeisl M, Hosseinzadeh-Attar MJ, Hensler M, Ruzickova J \& Kopecky J (2006) Polyunsaturated fatty acids of marine origin induce adiponectin in mice fed a high-fat diet. Diabetologia 49, 394-397.

8. Neschen S, Morino K, Rossbacher JC, Pongratz RL, Cline GW, Sono S, Gillum M \& Shulman GI (2006) Fish oil regulates adiponectin secretion by a peroxisome proliferator-activated receptor- $\gamma$-dependent mechanism in mice. Diabetes 55, 924-928.

9. Fukuhara A, Matsuda M, Nishizawa M, et al. (2005) Visfatin: a protein secreted by visceral fat that mimics the effects of insulin. Science 307, 426-430.

10. Revollo JR, Körner A, Mills KF, et al. (2007) Nampt/PBEF/ Visfatin regulates insulin secretion in $\beta$ cells as a systemic NAD biosynthetic enzyme. Cell Metab 6, 363-375.

11. Sandeep S, Velmurugan K, Deepa R \& Mohan V (2007) Serum visfatin in relation to visceral fat, obesity, and type 2 diabetes mellitus in Asian Indians. Metabolism 56, 565-570.

12. Zhang YY, Gottardo L, Thompson R, Powers C, Nolan D, Duffy J, Marescotti MC, Avogaro A \& Doria A (2006) A visfatin promoter polymorphism is associated with low-grade inflammation and type 2 diabetes. Obesity 14, 2119-2126.

13. Sun G, Bishop J, Khalili S, Vasdev S, Gill V, Pace D, Fitzpatrick D, Randell E, Xie YG \& Zhang H (2007) Serum visfatin concentrations are positively correlated with serum 
triacylglycerols and down-regulated by overfeeding in healthy young men. Am J Clin Nutr 85, 399-404.

14. Pagano C, Pilon C, Olivieri M, Mason P, Fabris R, Serra R, Milan G, Rossato M, Federspil G \& Vettor R (2006) Reduced plasma visfatin/pre-B cell colony-enhancing factor in obesity is not related to insulin resistance in humans. J Clin Endocrinol Metab 91, 3165-3170.

15. Boucher J, Masri B, Daviaud D, et al. (2005) Apelin, a newly identified adipokine up-regulated by insulin and obesity. Endocrinology 146, 1764-1771.

16. Heinonen MV, Purhonen AK, Miettinen P, Pääkkönen $M$, Pirinen E, Alhava E, Akerman K \& Herzig KH (2005) Apelin, orexin-A and leptin plasma levels in morbid obesity and effect of gastric banding. Regul Pept 130, 7-13.

17. Kralisch S, Lossner U, Bluher M, Paschke R, Stumvoll M \& Fasshauer M (2007) Growth hormone induces apelin mRNA expression and secretion in mouse 3T3-L1 adipocytes. Regul Pept 139, 84-89.

18. Castan-Laurell I, Boucher J, Dray C, Daviaud D, Guigne C \& Valet P (2005) Apelin, a novel adipokine over-produced in obesity: friend or foe? Mol Cell Endocrinol 245, 7-9.

19. Aas V, Rokling-Andersen MH, Kase ET, Thoresen GH \& Rustan AC (2006) Eicosapentaenoic acid (20:5n-3) increases fatty acid and glucose uptake in cultured human skeletal muscle cells. J Lipid Res 47, 366-374.

20. Seoane J, Barbera A, Telemaque-Potts S, Newgard CB \& Guinovart JJ (1999) Glucokinase overexpression restores glucose utilization and storage in cultured hepatocytes from male Zucker diabetic fatty rats. J Biol Chem 274, 31833-31838.

21. Delarue J, LeFoll C, Corporeau C \& Lucas D (2004) n-3 Long chain polyunsaturated fatty acids: a nutritional tool to prevent insulin resistance associated to type 2 diabetes and obesity? Reprod Nutr Dev 44, 289-299.

22. Perez-Echarri N, Perez-Matute P, Martinez JA, Marti A \& Moreno-Aliaga MJ (2005) Serum and gene expression levels of leptin and adiponectin in rats susceptible or resistant to diet-induced obesity. J Physiol Biochem 61, 333-342.

23. Kusunoki M, Tsutsumi K, Hara T, et al. (2003) Ethyl icosapentate (omega-3 fatty acid) causes accumulation of lipids in skeletal muscle but suppresses insulin resistance in OLETF rats. Otsuka Long-Evans Tokushima Fatty. Metabolism 52, 30-34.

24. Nobukata H, Ishikawa T, Obata M \& Shibutani Y (2000) Long-term administration of highly purified eicosapentaenoic acid ethyl ester prevents diabetes and abnormalities of blood coagulation in male WBN/Kob rats. Metabolism 49, 912-919.

25. Marrades MP, Milagro FI, Martinez JÁ \& Moreno-Aliaga MJ (2006) Differential expression of aquaporin 7 in adipose tissue of lean and obese high fat consumers. Biochem Biophys Res Commun 339, 785-789.

26. Newgard CB, Hirsch LJ, Foster DW \& McGarry JD (1983) Studies on the mechanism by which exogenous glucose is converted into liver glycogen in the rat. A direct or an indirect pathway? J Biol Chem 258, 8046-8052.

27. Milagro FI, Gomez-Ambrosi J, Forga L \& Martinez JA (1999) A $\beta 3$-adrenergic agonist increases muscle GLUT1/GLUT4 ratio, and regulates liver glucose utilization in diabetic rats. Diabetes Obes Metab 1, 97-104.

28. Baginski ES, Foa PP \& Zak B (1974) Glucose-6-phosphatase. In Methods of Enzymatic Analysis, vol. 2, pp. 876-880 [Hll Bergemeyer, editor]. New York: Academic Press.

29. Bradford MM (1976) A rapid and sensitive method for the quantitation of microgram quantities of protein utilizing the principle of protein-dye binding. Anal Biochem 72, 248-254.

30. Matthews DR, Hosker JP, Rudenski AS, Naylor BA, Treacher DF \& Turner RC (1985) Homeostasis model assessment: insulin resistance and $\beta$-cell function from fasting plasma glucose and insulin concentrations in man. Diabetologia 28, 412-419.

31. Wallace TM, Levy JC \& Matthews DR (2004) Use and abuse of HOMA modeling. Diabetes Care 27, 1487-1495.

32. Milagro FI, Campión J \& Martínez JA (2006) Weight gain induced by high-fat feeding involves increased liver oxidative stress. Obesity 14, 1118-1123.

33. Flanagan AM, Brown JL, Santiago CA, Aad PY, Spicer LJ \& Spicer MT (2008) High-fat diets promote insulin resistance through cytokine gene expression in growing female rats. J Nutr Biochem 19, 505-513.

34. Choi JS, Koh IU, Jung MH \& Song J (2007) Effects of three different conjugated linoleic acid preparations on insulin signalling, fat oxidation and mitochondrial function in rats fed a high-fat diet. Br J Nutr 98, 264-275.

35. Ribot J, Rodríguez AM, Rodríguez E \& Palou A (2008) Adiponectin and resistin response in the onset of obesity in male and female rats. Obesity 16, 723-730.

36. Havel PJ (2004) Update on adipocyte hormones: regulation of energy balance and carbohydrate/lipid metabolism. Diabetes 53, Suppl. 1, S143-S151.

37. Sethi JK \& Vidal-Puig A (2005) Visfatin: the missing link between intra-abdominal obesity and diabetes? Trends Mol Med 11, 344-347.

38. Klöting N \& Klöting I (2005) Visfatin: gene expression in isolated adipocytes and sequence analysis in obese WOKW rats compared with lean control rats. Biochem Biophys Res Commun 332, 1070-1072.

39. Wang P, van Greevenbroek MM, Bouwman FG, Brouwers MC, van der Kallen CJ, Smit E, Keijer J \& Mariman EC (2007) The circulating PBEF/NAMPT/visfatin level is associated with a beneficial blood lipid profile. Pflugers Arch 4546, 971-976.

40. Berndt J, Klöting N, Kralisch S, Kovacs P, Fasshauer M, Schön MR, Stumvoll M \& Blüher M (2005) Plasma visfatin concentrations and fat depot-specific mRNA expression in humans. Diabetes 54, 2911-2916.

41. Samal B, Sun Y, Stearns G, Xie C, Suggs S \& McNiece I (1994) Cloning and characterization of the cDNA encoding a novel human pre-B-cell colony-enhancing factor. Mol Cell Biol 14, 1431-1437.

42. Krzyzanowska K, Mittermayer F, Krugluger W, Kopp HP \& Schernthaner G (2006) Increase in visfatin after weight loss induced by gastroplastic surgery. Obesity 14, 1886-1889.

43. Pérez-Matute P, Marti A, Martínez JA, Fernández-Otero MP, Stanhope KL, Havel PJ \& Moreno-Aliaga MJ (2005) Eicosapentaenoic fatty acid increases leptin secretion from primary cultured rat adipocytes: role of glucose metabolism. Am J Physiol Regul Integr Comp Physiol 288, 1682-1688.

44. Stephens JM \& Vidal-Puig AJ (2006) An update on visfatin/ pre-B cell colony-enhancing factor, an ubiquitously expressed, illusive cytokine that is regulated in obesity. Curr Opin Lipidol 17, 128-131.

45. Li L, Yang G, Li Q, Tang Y, Yang M, Yang H \& Li K (2006) Changes and relations of circulating visfatin, apelin, and resistin levels in normal, impaired glucose tolerance, and type 2 diabetic subjects. Exp Clin Endocrinol Diabetes 114, 544-548.

46. Wen Y, Wang HW, Wu J, Lu HL, Hu XF \& Cianflone K (2006) Effects of fatty acid regulation on visfatin gene expression in adipocytes. Chin Med J 119, 1701-1708.

47. Choi KC, Ryu OH, Lee KW, Kim HY, Seo JA, Kim SG, Kim $\mathrm{NH}$, Choi DS, Baik SH \& Choi KM (2005) Effect of PPAR- $\alpha$ and $-\gamma$ agonist on the expression of visfatin, adiponectin, and TNF- $\alpha$ in visceral fat of OLETF rats. Biochem Biophys Res Commun 336, 747-753.

48. Choi KC, Lee SY, Yoo HJ, Ryu OH, Lee KW, Kim SM, Baik SH \& Choi KM (2007) Effect of PPAR- $\delta$ agonist on the expression of visfatin, adiponectin, and resistin in rat adipose 
tissue and 3T3-L1 adipocytes. Biochem Biophys Res Commun 357, 62-67.

49. Haider DG, Schaller G, Kapiotis S, Maier C, Luger A \& Wolzt M (2006) The release of the adipocytokine visfatin is regulated by glucose and insulin. Diabetologia 49, 1909-1914.

50. MacLaren R, Cui W \& Cianflone K (2007) Visfatin expression is hormonally regulated by metabolic and sex hormones in 3T3L1 pre-adipocytes and adipocytes. Diabetes Obes Metab 9, 490-497.

51. Garcia-Diaz D, Campion J, Milagro FI \& Martinez JA (2007) Adiposity dependent apelin gene expression: relationships with oxidative and inflammation markers. Mol Cell Biochem 305, 87-94.

52. Daviaud D, Boucher J, Gesta S, et al. (2006) TNF $\alpha$ up-regulates apelin expression in human and mouse adipose tissue. FASEB $J$ 20, $1528-1530$.

53. Higuchi K, Masaki $\mathrm{T}$, Gotoh $\mathrm{K}$, Chiba S, Katsuragi I, Tanaka K, Kakuma T \& Yoshimatsu H (2007) Apelin, an APJ receptor ligand, regulates body adiposity and favors the mRNA expression of uncoupling proteins in mice. Endocrinology 148, 2690-2697.

54. Pedersen O, Kahn CR, Flier JS \& Kahn BB (1991) High fat feeding causes insulin resistance and a marked decrease in the expression of glucose transporters (Glut 4) in fat cells of rats. Endocrinology 129, 771-777.

55. Takahashi Y \& Ide T (2000) Dietary $n-3$ fatty acids affect mRNA level of brown adipose tissue uncoupling protein 1 , and white adipose tissue leptin and glucose transporter 4 in the rat. Br J Nutr 84, 175-184.

56. Kahn BB \& Pedersen O (1993) Suppression of GLUT4 expression in skeletal muscle of rats that are obese from high fat feeding but not from high carbohydrate feeding or genetic obesity. Endocrinology 132, 13-22.

57. Peyron-Caso E, Fluteau-Nadler S, Kabir M, Guerre-Millo M, Quignard-Boulangé A, Slama G \& Rizkalla SW (2002) Regulation of glucose transport and transporter 4 (GLUT-4) in muscle and adipocytes of sucrose-fed rats: effects of $n-3$ polyand monounsaturated fatty acids. Horm Metab Res 34, 360-366.

58. Taouis M, Dagou C, Ster C, Durand G, Pinault M \& Delarue J (2002) n-3 Polyunsaturated fatty acids prevent the defect of insulin receptor signaling in muscle. Am J Physiol Endocrinol Metab 282, E664-E671.

59. Minami A, Ishimura N, Sakamoto S, Takishita E, Mawatari K, Okada K \& Nakaya Y (2002) Effect of eicosapentaenoic acid ethyl ester $v$. oleic acid-rich safflower oil on insulin resistance in type 2 diabetic model rats with hypertriacylglycerolaemia. Br J Nutr 87, 157-162.

60. Daniele N, Bordet JC \& Mithieux G (1997) Unsaturated fatty acids associated with glycogen may inhibit glucose-6 phosphatase in rat liver. $J$ Nutr 127, 2289-2292.

61. Zulet MA, Barber A, Garcin H, Higueret P \& Martinez JA (1999) Alterations in carbohydrate and lipid metabolism induced by a diet rich in coconut oil and cholesterol in a rat model. J Am Coll Nutr 18, 36-42. 